\title{
Braking Force Distribution Strategy for Comfort of Tractor and Semi-Trailer Combination
}

\author{
Hongyu Zhenga , Zongyu Liu and Wenkai Xu \\ State Key Laboratory of Automotive Simulation and Control,Jilin University,Changchun 130025, \\ China \\ azhenghy@jlu.edu.cn
}

\section{Keywords: Tractor/semi-trailer combination; Dynamic model; Coupling force control}

\begin{abstract}
For the purpose of comfort enhancement during the braking process of tractor/semi-trailer combination vehicles, and in order to achieve a smooth braking deceleration establishment in which the braking force of a vehicle only relates to the braking signal it receives and yet is not affected by the gross mass of a semi-trailer, a braking force distribution algorithm is proposed. The algorithm, based on Electronically controlled Braking System, determines the semi-trailer's mass and vertical load of each axle, distributing the braking force of each axle according to its own vertical load. By using the TruckSim and MATLAB/Simulink, the simulation results show that, with such algorithm, braking deceleration of tractor/semi-trailer combination is only depend on the braking signal it receives, standing free from the impact of semi-trailer mass. Moreover, braking deceleration achieves a smooth establishment, which promotes its comfort. In addition, each axle gets a harmonious braking force distribution, thus achieving an ideal coupling force between tractor and semi-trailer.
\end{abstract}

\section{Introduction}

To meet the needs of rapid economic development, and to cater to the growing demands of logistics and transport, China's road network construction and highway transport have made enormous strides. Semi-trailers have been widely used in road transport operation for its low cost, good flexibility and huge carrying capacity. The transporting volume by tractor/semitrailer combination is in large proportion among the total volume, therefore, the safety reliability and operating condition of semi-trailers were crucial to meet the operation standard and assurance of transport. Previous research mainly focus on the maximum braking performance and brake stability. Bushman.G and M.NA KAZAWA proposed the Electronical Braking force Distribution system(EBD), in which, the brake pressure in wheel cylinder is regulated before the Anti-Lock Brake System (ABS) works, thus the ideal braking force distribution between the front and rear axle is achieved, the maximum braking performance and brake stability are also guaranteed[1,2]. These system is well applied to passenger vehicles, however, most commercial vehicles are equipped with air brake system, the unbalanced distribution of braking force and the collision between tractor and semi-trailer resulting from air transfer delay between tractor and trailer will increase the instability of the tractor and trailer, decrease the riding comfort during the braking process and exacerbate driver's fatigue[3]. Moreover, in the conventional brake system, the travel of brake paddle just control the braking force, owing that semi-trailer load varies from trip to trip, which can not be estimated by the driver, therefore, the driver can hardly control vehicle's deceleration precisely and the security is threatened. Also, the uncertainty of vehicle mass will undermine the optimal braking force among axles. Electronically Controlled Braking System (EBS) makes it possible to optimize the braking force distribution and eliminate the air transfer delay between tractor and trailer[4]. And a load sensor on the semi-trailer's axle makes it possible to estimate the trailer's mass. The paper aims at, via the use of Electronically controlled Braking System (EBS) and a load sensor on semi-trailer's axle, estimating semi-trailer's mass, and optimizing the braking force distribution, in order that the vehicle deceleration is just dependent on the brake signal the vehicle receives, while staying free from the impact of semi-trailer mass. Also, the vehicle is expected to achieve a smooth deceleration establishment, which will enhance the comfort 
during braking process. In addition, with a view to getting a harmonious braking force distribution among axles, an ideal coupling force was achieved. The algorithm was simulated by TruckSim and MATLAB/Simulink[5], in order to verify its effectiveness.

\section{Tractor and Semi-trailer Dynamic Model}

The combination is modeled as two rigid body hinges to each other, and suspension is ignored.

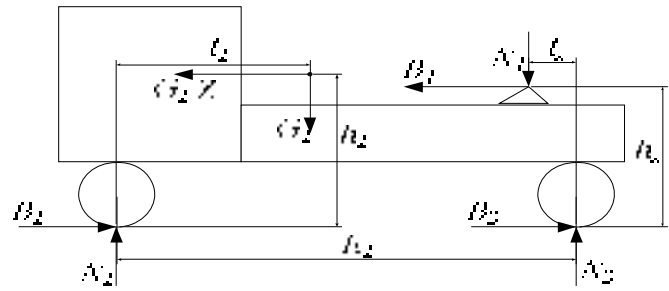

Fig. 1 Tractor dynamic model

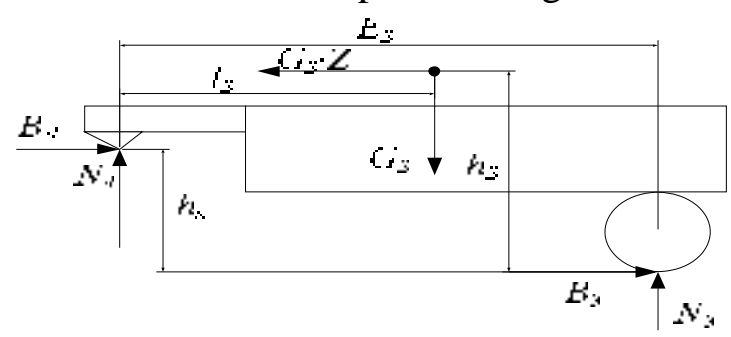

Fig. 2 Semi-Trailer dynamic model

Where $h_{1}$ is the distance from tractor mass $C G$ to the road, $h_{s}$ is the distance from coupling device to the road, $\mathrm{E}_{1}$ is the distance between tractor's two axles, $1_{1}$ is the distance between tractor mass CG and the front axle, $1_{\mathrm{s}}$ is the distance from coupling device to the rear axle. $\mathrm{Z}$ is the relative deceleration(that is, $\mathrm{Z}=\mathrm{d} / \mathrm{g}$ ), $\mathrm{N}_{1}, \mathrm{~N}_{2}$ are the vertical load of tractor's front and rear axle, $\mathrm{N}_{4}$ is the vertical force existing on the coupling force, $\mathrm{B}_{1}, \mathrm{~B}_{2}$ are the braking force of front and rear axle, $\mathrm{B}_{4}$ is the longitude force existing on the coupling force. For the semi-trailer, $G_{2}$ is the weight of semi-trailer, $E_{2}$ is the distance between coupling device and semi-trailer's axle, $l_{2}$ is the distance from semi-trailer's mass CG to the coupling device, $\mathrm{h}_{2}$ is the distance between semi-trailer's mass $\mathrm{CG}$ to the road, $\mathrm{B}_{3}$ is the braking force of semi-trailer' axle, $\mathrm{N}_{3}$ is vertical load on its axle.

The tractor unit has three equations of motion

Equation of the horizontal direction

$B_{4}+G_{1} \cdot Z=B_{1}+B_{2}$

Equation of the vertical direction

$N_{1}+N_{2}=G_{1}+N_{4}$

Torque of front axle

$N_{2} \cdot E_{1}+B_{4} \cdot h_{s}+G_{1} \cdot Z \cdot h_{1}=G_{1} \cdot l_{1}+N_{4} \cdot\left(E_{1}-l_{s}\right)$

(3)

As for the semi-trailer, three equation of motion are also presented

Equation of the horizontal direction

$B_{4}+B_{3}=G_{2} \cdot Z$

Equation of the vertical direction

$N_{4}+N_{3}=G_{2}$

Torque of the coupling device

$B_{3} \cdot h_{s}+N_{3} \cdot E_{2}+G_{2} \cdot Z \cdot\left(h_{2}-h_{s}\right)=G_{2} \cdot l_{2}$

The optimal braking condition is achieved when each axle gets the same utilized braking force coefficient, which means the ratio of the braking force on each axle and its own vertical load are the same. Under such condition, the ratio of longitude force and vertical force on the coupling device is also the same[6], that is :

$B_{i} / N_{i}=Z$

From Eq.1-Eq.9:

$G_{2}=N_{3} \cdot\left(Z \cdot h_{s}+E_{2}\right) /\left(l_{2}+Z \cdot\left(h_{2}+h_{s}\right)\right)$

(8)

$N_{1}=G_{1} \cdot\left(E_{1} \cdot l_{1}+Z \cdot h_{1}\right) / E_{1}+N_{3} \cdot\left(l_{s}+Z \cdot h_{s}\right)\left(E_{2} \cdot l_{2}+Z \cdot h_{2}\right) /\left(E_{1} \cdot\left(l_{2}+Z \cdot\left(h_{2}+h_{s}\right)\right)\right)$

$N_{2}=G_{1} \cdot\left(l_{1}+Z \cdot h_{1}\right) / E_{1}+N_{3} \cdot\left(E_{1} \cdot l_{s}+Z \cdot h_{s}\right) \cdot\left(E_{2} \cdot l_{2}+Z \cdot h_{2}\right) /\left(E_{1} \cdot\left(l_{2}+Z \cdot\left(h_{2}+h_{s}\right)\right)\right.$

Thus, the ideal braking force is determined: 


$$
B_{i}=Z \cdot N_{i}
$$

\section{Braking Force Distribution Model Based on EBS}

During braking progress, braking effect relies mostly on its algorithm. PID is the most commonly used feedback controller for its good stability, simple manipulation and convenience when adjusting. When the algorithm detects the deviation between the real deceleration and target deceleration, PID controller is started. The algorithm gets the output $\mathrm{u}_{(\mathrm{t})}$, which is calculated by the PID controller, and is to determine the total additional braking force. The relationship between $\mathrm{u}_{(\mathrm{t})}$ and $\Delta B$ is given as:

$$
\Delta B=u_{(t)} \cdot\left(G_{1}+G_{2}\right)
$$

Then the algorithm proportionally determines the braking force of each axle according to the vertical load of each axle, which is calculated by the model.

$\Delta B_{1} / N_{1}=\Delta B_{2} / N_{2}=\Delta B_{3} / N_{3}$

Where $\Delta \mathrm{B}_{\mathrm{i}}$ is the additional braking force distributed to the corresponding axle.

The TruckSim and MATLAB/Simulink model shown as Fig.3:

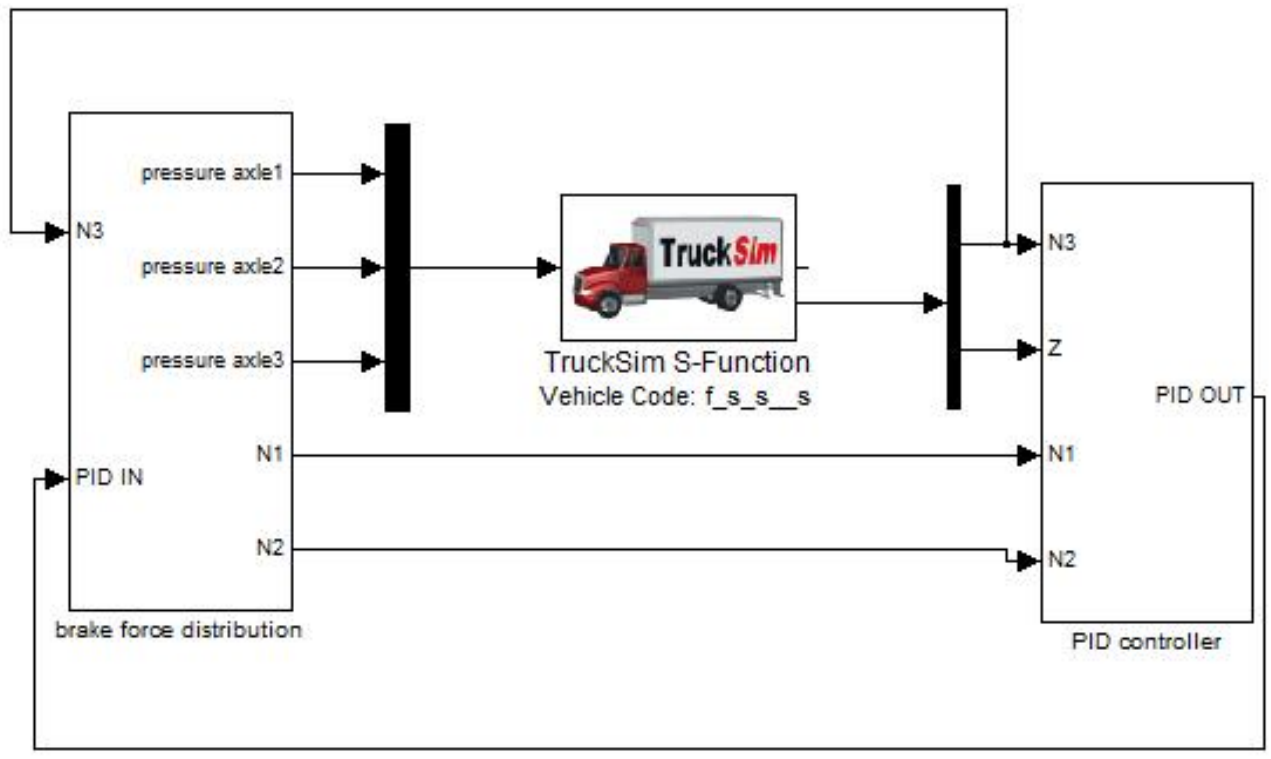

Fig.3 TruckSim and MATLAB/Simulink model

\section{Simulation Results}

Vehicle decceleration establishment under various target decelerations. The simulation is conducted in various semi-trailer's load condition. In the test, $G_{2}=970000 \mathrm{~N}$, when the semi-trailer is full-loaded, and $\mathrm{G}_{2}$ when middle-load and unload is respectively $67000 \mathrm{~N}$ and $37000 \mathrm{~N}$.

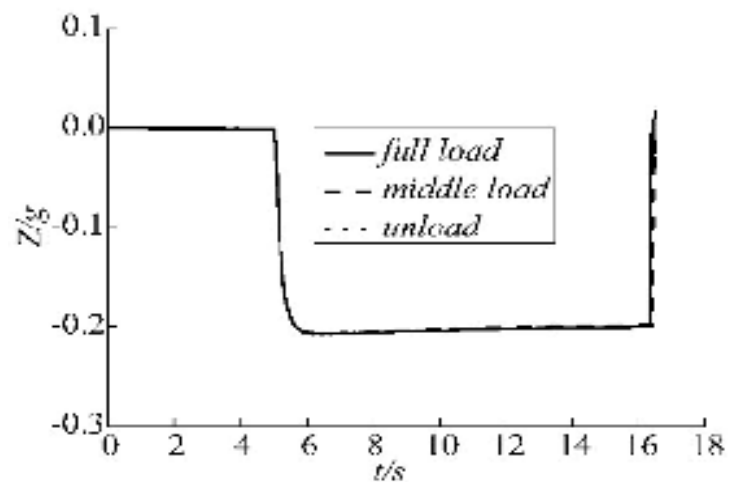

Fig.4 when target deceleration is $0.2 \mathrm{~g}$

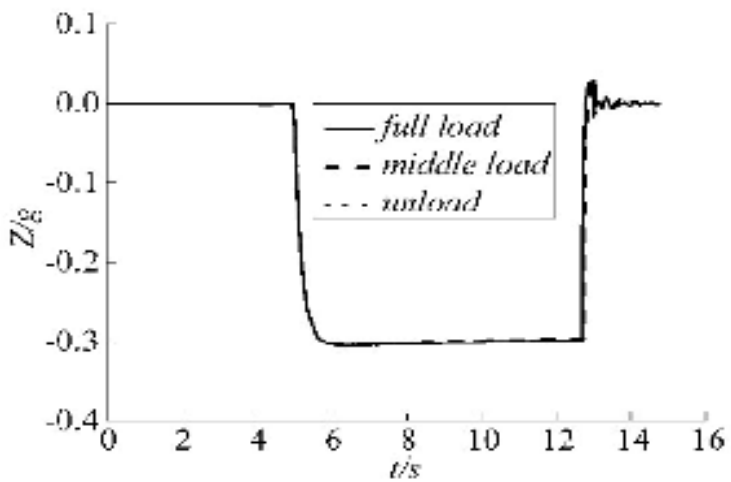

Fig.5 when target deceleration is $0.3 \mathrm{~g}$ 


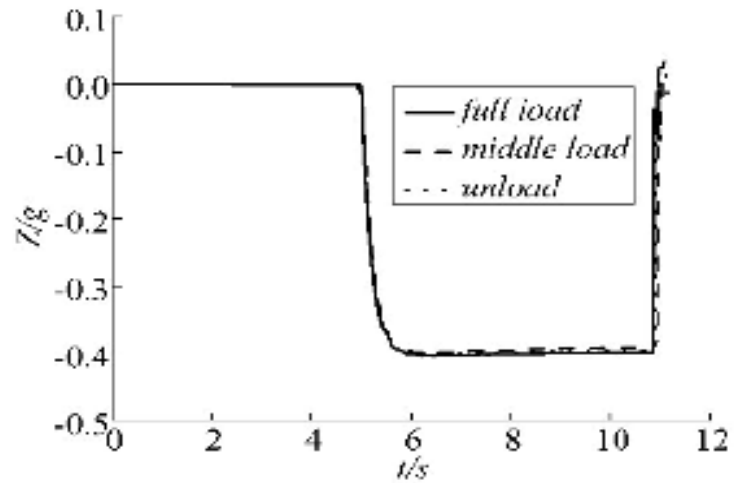

Fig.6 when target deceleration is $0.4 \mathrm{~g}$

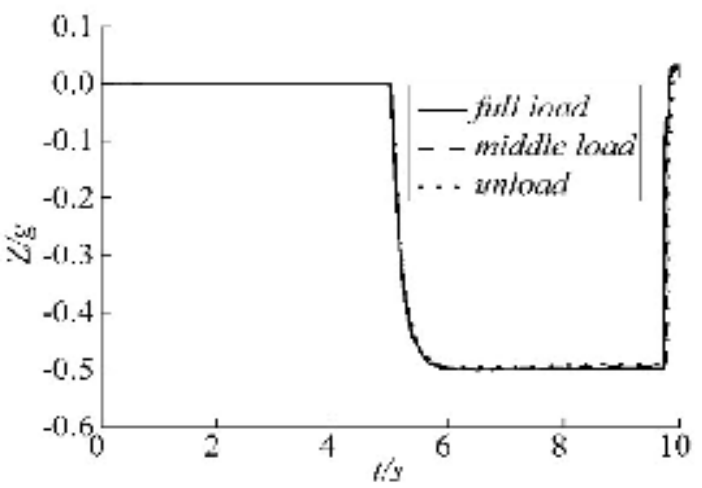

Fig. 7 when target deceleration is $0.5 \mathrm{~g}$

According to Fig.4-Fig.7, the vehicle could gain target deceleration within 0.5 second, and the deceleration establishment curve under different load conditions shows good similarity, which indicates that deceleration is just depend on the target deceleration, which would not be affected by the impact of semi-trailer mass. And deceleration is smoothly established, which promotes comfort during braking process.

The ratio of longitude force and vertical load on each axle and coupling device. In this test, the vehicle brake at $\mathrm{T}=5 \mathrm{~s}$, and the target deceleration is $0.6 \mathrm{~g}$.

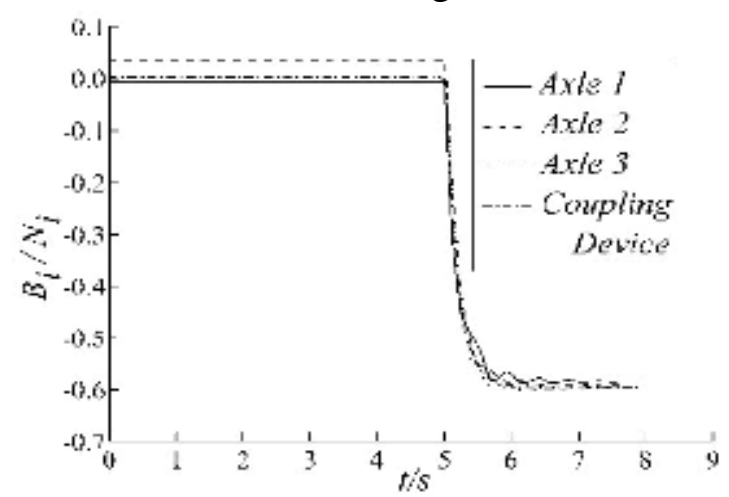

Fig. 8 unload

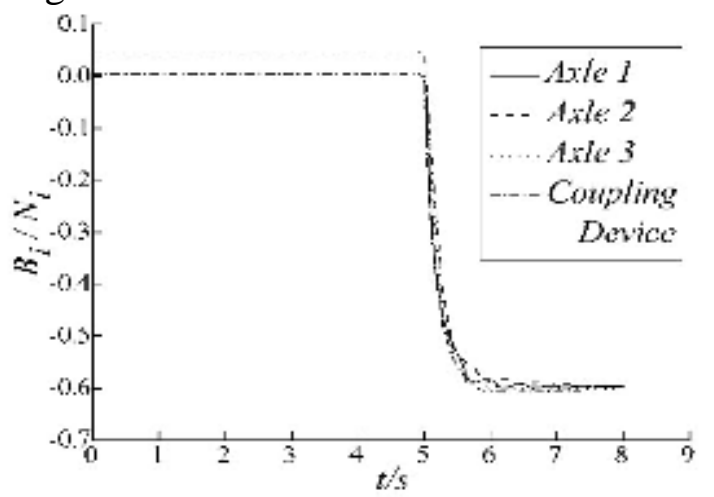

Fig.9 full load

Fig.8-Fig.9 show the ratio of longitude force and vertical load on each axle and coupling device under full load and unload conditions. Owing to the fact that the second axle is driven axle while others are not, the radio of the second axle is different from other axles before the brake. As is shown in Fig.8-Fig.9, it's obvious that, when braking, the vehicle could achieve the same ratio of longitude force and vertical load on each axle and coupling device under different load conditions. It means that the vehicle achieves a good braking force distribution under different load condition, and an ideal coupling force is achieved.

\section{Conclusion}

In the paper, the load variation in semi-trailer is addressed for tractor/semitrailer combination braking comfort. The algorithm proposed in the paper is used to balance the braking force among axles and promote comfort by utilizing Electronically controlled Braking System (EBS) and a load sensor. Vehicle with such algorithm could well achieve target deceleration, while braking deceleration only depends on the braking signal, which would not be affected by the impact of semi-trailer mass. Also, deceleration is smoothly established, which promotes the comfort during the braking process. In addition, the algorithm can well distribute the braking force among axles, and thus, an ideal coupling force is achieved.

\section{Acknowledgment}


This work is supported by National Youth Natural Science Foundation of China (51105165) and China Postdoctoral Science Foundation (20110490158).

\section{References}

[1]BUSHMAN, G., et al.: International Congress \& Exposition (Detroit, MI, USA, Febraury, 1992), Vol.1, p.76.

[2]M. NAKAZAWA, O. ISOBE, S. TAKAHASHI, Y. WATANABE: Vehicle System Dynamic, Vol.24 (1995) No.4-5, p.413.

[3]Jinglai Wu, Hongchang Zhang, Yunqing Zhang, Liping Chen: SAE World Congress \& Exhibition (Detroit, Michigan, United States, 20, april, 2009), Vol.1, p.87.

[4]Information on http://www.wabco-auto.com/products wabco/brake-stability-control.

[5]Mechanical Simulation Corporation: TruckSim 8.0 (2009), p.1.

[6]C. BEYER, H. SCHRAMM, J. WREDE: Truck \& Bus Meeting \& Exposition (Indianapolis, 16-18, November, 1998), Vol.1, p.121. 